\title{
Beyond return of spontaneous circulation: update on post-cardiac arrest management in the intensive care unit
}

\author{
Yew Woon $\underline{C h i a}^{1}$, FRCP, EDIC, Shir Lynn $\underline{\mathrm{Lim}}^{2}$, MBBS, MRCP, Julian Kenrick Loh${ }^{3}$, MB BCh BAO, MRCP, \\ Benjamin Sieu-Hon Leong ${ }^{4}$, MBBS, MRCSEd, Marcus Eng Hock Ong ${ }^{5,6}$, MBBS, MPH; \\ Singapore National Targeted Temperature Management Workgroup
}

\begin{abstract}
A well-functioning chain of survival is critical for good outcomes following out-of-hospital cardiac arrest, a major public health concern in Singapore. While the percentage of survivors to hospital admission has increased over the years, the percentage of survivors to hospital discharge and the number of patients with good neurological recovery can be greatly improved. This underscores the urgent need to focus on 'post-cardiac arrest care', the fifth link in the chain of survival, to improve the outcomes of patients who are admitted to the intensive care unit (ICU) after return of spontaneous circulation. This review builds on earlier recommendations of the Singapore National Targeted Temperature Management Workgroup in 2017 to provide a focused update on post-cardiac arrest management and a practical guide for physicians managing resuscitated patients with cardiac arrest in the ICU.
\end{abstract}

Keywords: intensive care unit, post-cardiac arrest syndrome, targeted temperature management

\section{CASE VIGNETTE (PART 1)}

Ms T was a 28-year-old woman with no significant past medical history. She experienced chest pain and collapsed at her workplace at 1120 hours. On arrival of the paramedics, she was in pulseless electrical activity. Adrenaline was administered and she developed ventricular fibrillation (VF). Upon defibrillation, she had transient return of spontaneous circulation (ROSC). On arrival at the emergency department, the patient had recurrent $V F$, which required further defibrillations and adrenaline. Amiodarone was also administered. There was still no sustained ROSC at 1230 hours (which was after 23 minutes of 'no flow' and 47 minutes of 'low flow' time). At that time, arterial blood gas analysis revealed $\mathrm{pH} 6.89$, partial pressure of carbon dioxide in arterial blood $\left(\mathrm{PaCO}_{2}\right) 34 \mathrm{mmHg}$, partial pressure of oxygen in arterial blood $\left(\mathrm{PaO}_{2}\right) 117 \mathrm{mmHg}$, bicarbonate $\left(\mathrm{HCO}_{3}\right) 7 \mathrm{mmol} / \mathrm{L}$, base excess $-27 \mathrm{mmol} / \mathrm{L}$ and arterial oxygen saturation $\left(\mathrm{SaO}_{2}\right)$ $94 \%$. The emergency physician and cardiologist made a joint decision to send the patient to the cardiac catheterisation laboratory on a mechanical chest compression device. Emergency coronary angiogram revealed a spontaneous left main stem dissection, for which percutaneous coronary intervention (PCl) was performed with implantation of a drug-eluting stent. The patient achieved sustained ROSC shortly after PCI with a total 'downtime' of 112 minutes and was transferred to the cardiac intensive care unit (ICU) for further management.

\section{INTRODUCTION}

Out-of-hospital cardiac arrest (OHCA) is a major public health concern in Singapore. Based on statistics from the Ministry of
Health, Singapore, the incidence of cardiac arrest increased from 26.5 to 52.7 patients per 100,000 population from 2011 to 2018 . $^{(1)}$ A well-functioning chain of survival is critical for good outcomes following OHCA. Improvements in pre-hospital interventions, such as bystander cardiopulmonary resuscitation, wider availability and usage of automated external defibrillators and technologies such as the myResponder App, have increased the percentage of survivors to hospital admission from $18.2 \%$ to $18.5 \%$. However, after admission to the ICU, survival to hospital discharge remains low at only $5.9 \%$. More importantly, among survivors, there is often significant neurological damage that imposes disabling immediate and longterm consequences on the patients, their families and the broader community. Of note, only $4.0 \%$ of patients with cardiac arrest in Singapore survive with moderately good to good neurological function. This underscores the importance of focusing on 'postcardiac arrest care', the fifth link in the chain of survival, to improve the outcomes of patients who are admitted to the ICU after ROSC.

Achieving ROSC is only the first step towards the goal of complete recovery after cardiac arrest. The complex pathophysiological processes that occur following global ischaemia during cardiac arrest and the subsequent reperfusion response during and after resuscitation are termed the 'PostCardiac Arrest Syndrome' (PCAS). ${ }^{(2)}$ PCAS comprises four components: post-cardiac arrest brain injury; post-cardiac arrest myocardial dysfunction; systemic ischaemic-reperfusion syndrome; and persistence of precipitating pathology, with brain injury accounting for most of the morbidity and mortality after ROSC. The optimal care of PCAS requires coordinated management of multiple organ systems, including targeted

\footnotetext{
${ }^{1}$ Cardiac Intensive Care Unit, Department of Cardiology, Tan Tock Seng Hospital, ${ }^{2}$ Department of Cardiology, National University Heart Centre Singapore, National University Hospital, ${ }^{3} \mathrm{C}$ ardiac Intensive Care Unit, Department of Cardiology, National Heart Centre Singapore, ${ }^{4}$ Department of Emergency Medicine, National University Hospital, ${ }^{5}$ Department of Emergency Medicine, Singapore General Hospital, ${ }^{6}$ Duke-NUS Medical School, Singapore

Correspondence: Dr Yew Woon Chia, Chairman, National Targeted Temperature Management Workgroup; Senior Consultant Cardiologist-Intensivist and Director, Cardiac Intensive Care Unit, Department of Cardiology, Tan Tock Seng Hospital, 11 Jalan Tan Tock Seng, Singapore 308433. yew_woon_chia@ttsh.com.sg
} 
temperature management (TTM). Depending on the cause of collapse and severity of PCAS, many patients will require multiorgan support, and the treatments that they receive during the post-resuscitation period significantly influence overall outcomes and, in particular, neurological recovery. ${ }^{(3)}$ Therefore, treatments to optimise ventilatory, haemodynamic and metabolic variables, together with TTM, should be initiated as soon as possible. This review builds on earlier recommendations of the Singapore National TTM Workgroup in 2017,(4) as well as the International Liaison Committee on Resuscitation (ILCOR) 2020 guidelines, ${ }^{(5)}$ to provide a focused update on post-cardiac arrest management (the 'A to I' approach) and a practical guide for physicians managing resuscitated patients with cardiac arrest in the ICU (Table I and Fig. 1).

\section{A - AIRWAY}

Patients who only have a brief period of cardiac arrest and respond immediately to resuscitation may achieve a return of normal cerebral function and may not require intubation if they are able to maintain their airway. However, if there is any doubt about the ability to protect airway such as a depressed conscious level, tracheal intubation and mechanical ventilation should be instituted. It is reasonable to consider using a tracheal tube with subglottic secretion drainage to reduce ventilator-associated pneumonia, which has a higher incidence during $\operatorname{TTM}^{(6,7)}$

\section{B - BREATHING Oxygenation}

Hypoxaemia $\left(\mathrm{PaO}_{2}<60 \mathrm{mmHg}\right.$ or $\mathrm{PaO}_{2}$ /fraction of inspired oxygen $\left[\mathrm{FiO}_{2}\right]$ ratio $<300$ ) increases the likelihood of further cardiac arrest and contributes to secondary brain injury. Conversely, hyperoxaemia $\left(\mathrm{PaO}_{2} \geq 300 \mathrm{mmHg}\right.$ ) has the potential to cause oxidative stress, worsening neurological injury and increasing mortality. ${ }^{(8,9)}$ The recommendation, therefore, is to target blood oxygen saturation $\left(\mathrm{SpO}_{2}\right)$ of $94 \%-98 \%$. We should also avoid using a high level of positive end expiratory pressure (PEEP; e.g. > $10 \mathrm{cmH}_{2} \mathrm{O}$ ), as high intra-thoracic pressures may reduce cerebral venous drainage, increasing cerebral blood volume and intracranial pressure (ICP). Thereafter, $\mathrm{FiO}_{2}$ should be titrated to achieve oxygenation targets.

\section{Ventilation}

Hypocapnia causes cerebral vasoconstriction and reduces cerebral blood flow, contributing to poorer neurological outcomes. Conversely, pilot studies have shown that mild hypercapnia is associated with better neurological prognosis in post-cardiac arrest patients. ${ }^{(10-13)}$ Until definitive studies supporting mild hypercapnia are reported, the current recommendation is to aim for normocapnia, i.e. target $\mathrm{PaCO}_{2} 35-45 \mathrm{mmHg}$. It may be reasonable to consider targeted therapeutic mild hypercapnia, i.e. $\mathrm{PaCO}_{2} 50-55 \mathrm{mmHg}$, if there is evidence of low cerebral oxygenation and no contraindications to mild hypercapnia such as raised ICP or severe metabolic acidosis. Although the in vivo $\mathrm{PaCO}_{2}$ decreases by $2 \mathrm{mmHg}$ for each degree Celsius below $37^{\circ} \mathrm{C}$, there is currently no recommendation for temperature correction of $\mathrm{CO}_{2}$. The use of end tidal carbon dioxide $\left(\mathrm{ETCO}_{2}\right)$ for continuous monitoring is invaluable and the $\mathrm{PaCO}_{2}-\mathrm{P}_{\mathrm{ET}} \mathrm{CO}_{2}$ gradient should be determined daily. Both hypothermia and the use of neuromuscular blocking agents can reduce $\mathrm{CO}_{2}$ production and increase the risk of hypocapnia. ${ }^{(14)}$ Routine lung protective ventilation strategies, i.e. tidal volume $6-8 \mathrm{~mL} / \mathrm{kg}$, predicted body weight and maintaining plateau pressure $\leq 30 \mathrm{cmH}_{2} \mathrm{O}$, should be employed to reduce the incidence of ventilator-induced lung injury. Chest radiography should be performed to confirm the positions of tracheal tube, gastric tube and central venous catheter, and to detect pulmonary oedema, pneumonia and complications arising from resuscitation (e.g. rib fractures).

\section{C - CIRCULATION Coronary angiography}

Acute coronary syndrome is a frequent cause of OHCA, and $59 \%-71 \%$ of patients with OHCA without an obvious noncardiac cause have an acute coronary lesion found on coronary angiography. ${ }^{(15)}$ As such, urgent coronary angiography should be performed in patients after ROSC if the electrocardiogram (ECG) shows ST-segment elevation (Class I recommendation by both American Heart Association [AHA] and European Society of Cardiology [ESC]). ${ }^{(16-19)}$ For patients with no ST-segment elevation, it is reasonable to consider emergent coronary angiography if they have a high probability of a coronary cause for the arrest and/or have ongoing electrical or haemodynamic instability (Class Ila recommendation by $\mathrm{AHA}$ and $\mathrm{ESC}) .{ }^{(17-20)}$

\section{Haemodynamic monitoring}

Treatment should be guided by blood pressure (BP), cardiac output, central venous oxygen saturation $\left(\mathrm{ScvO}_{2}\right)$, urine output and lactate clearance. An arterial cannula should be inserted for continuous BP monitoring. As cardiac function is often impaired after cardiac arrest, it is also reasonable to consider continuous cardiac output and continuous $\mathrm{ScvO}_{2}$ monitoring. Serial focused ultrasonography for fluid responsiveness and echo-Doppler techniques to monitor stroke volume may also be performed.

\section{Haemodynamic targets}

Although the optimal target for mean arterial pressure (MAP) remains debatable, it is recommended to consider the patient's baseline BP and any evidence of raised ICP or acute kidney injury. In the absence of invasive ICP monitoring, an ultrasonography assessment of the optic nerve sheath diameter (ONSD) $>5 \mathrm{~mm}$ correlates well with an ICP $>20 \mathrm{cmH}_{2} \mathrm{O} .{ }^{(21)}$ During PCAS, cerebral autoregulation is impaired and cerebral blood flow varies directly with cerebral perfusion pressure. ${ }^{(22)}$ The recommended MAP target is at least $65 \mathrm{mmHg}$, and a higher MAP target (e.g. $80-85 \mathrm{mmHg}$ ) may be reasonable if the patient has chronic hypertension, or evidence of raised ICP or end-organ hypoperfusion.

\section{Bradycardia}

Bradycardia is common during induced mild hypothermia. It usually does not result in haemodynamic compromise and may be associated with better neurological outcomes. ${ }^{(23)}$ Therefore, there is 
Table I. Summary of recommendations for post-cardiac arrest management.

\begin{tabular}{|c|c|}
\hline \multirow[t]{2}{*}{ No. } & Recommendation \\
\hline & A - Airway \\
\hline \multirow[t]{2}{*}{1} & Use ETT with subglottic secretion drainage to reduce VAP \\
\hline & B - Breathing \\
\hline 2 & Target $\mathrm{SpO}_{2} 94 \%-98 \%$ (use lowest $\mathrm{FiO}_{2} \&$ avoid PEEP $>10 \mathrm{cmH}_{2} \mathrm{O}$ ) \\
\hline 3 & Target $\mathrm{PaCO}_{2} 35-45 \mathrm{mmHg}$ (may consider mild hypercapnia if low cerebral oxygenation and no evidence of raised ICP and pH > 7.2) \\
\hline \multirow[t]{2}{*}{4} & Use lung protective ventilation strategies (tidal volume $6-8 \mathrm{~mL} / \mathrm{kg} P B W \&$ Pplateau $\leq 30 \mathrm{cmH}_{2} \mathrm{O}$ ) \\
\hline & C - Circulation \\
\hline 5 & Emergent coronary angiography for patients with cardiac arrest if ECG shows STEMI and no treatment limitations \\
\hline 6 & Consider coronary angiography if no STEMI but likely coronary cause for cardiac arrest and/or electrical or haemodynamic instability \\
\hline 7 & Continuous BP monitoring (may consider continuous cardiac output/ScvO ${ }_{2}$ monitoring if available) \\
\hline \multirow[t]{2}{*}{8} & $\begin{array}{l}\text { Target MAP at least } 65 \mathrm{mmHg} \text { (may consider higher MAP target if baseline hypertension, evidence of raised ICP or end-organ } \\
\text { hypoperfusion, e.g. AKI) }\end{array}$ \\
\hline & D - Disability (neurology) \\
\hline 9 & CEEG monitoring (may consider sedation monitors with continuous frontal EEG monitoring as alternative) \\
\hline 10 & Spot EEG if seizures suspected and no cEEG monitoring \\
\hline 11 & Continuous cerebral regional oxygen saturation monitoring \\
\hline 12 & Ultrasonography ONSD to estimate ICP \\
\hline \multirow[t]{2}{*}{13} & Use short-acting sedative medications \\
\hline & E - Electrolytes \\
\hline 14 & Target sodium 140-145 mmol/L (may consider higher sodium target if evidence of raised ICP) \\
\hline \multirow[t]{2}{*}{15} & $\begin{array}{l}\text { Accept mild hypokalaemia } 3.0-3.5 \mathrm{mmol} / \mathrm{L} \text { if no significant arrhythmias (avoid aggressive replacement to prevent rebound } \\
\text { hyperkalaemia during rewarming) }\end{array}$ \\
\hline & F - Fluids \\
\hline \multirow[t]{2}{*}{16} & Avoid hypotonic solutions and use balanced electrolyte solutions \\
\hline & G - Gastrointestinal feeding and glucose \\
\hline 17 & Start trophic enteral feeding early \\
\hline \multirow[t]{2}{*}{18} & Target blood glucose 6-10 mmol/L (use insulin infusion when on vasopressors or hypothermia therapy) \\
\hline & H - Hypo/hyperthermia and Haematology \\
\hline 19 & $\begin{array}{l}\text { TTM for all adult patients with OHCA/IHCA who remain comatose after ROSC regardless of initial cardiac rhythm (note that bleeding diathesis, } \\
\text { sepsis, bradycardia and prolonged QT interval are not contraindications to TTM, but a higher target temperature may be selected, up to } 36^{\circ} \mathrm{C} \text { ) }\end{array}$ \\
\hline 20 & $\begin{array}{l}\text { TTM at either } 33^{\circ} \mathrm{C} \text { or } 36^{\circ} \mathrm{C} \text {, with rapid induction to reach target temperature and maintain at target temperature with minimal } \\
\text { fluctuations }\end{array}$ \\
\hline 21 & $\begin{array}{l}\text { Use a cooling device with continuous temperature feedback using thermistor measuring oesophageal or urinary bladder } \\
\text { temperature }\end{array}$ \\
\hline 22 & $\begin{array}{l}\text { Maintain at target temperature for at least } 24 \mathrm{hr} \text { (may consider longer maintenance at target temperature if prolonged no flow and/or } \\
\text { low flow time) }\end{array}$ \\
\hline 23 & Slow controlled rewarming at $0.1^{\circ} \mathrm{C}-0.25^{\circ} \mathrm{C}$ per hour to $37^{\circ} \mathrm{C}$ \\
\hline 24 & Maintain patient at $37^{\circ} \mathrm{C}$ (controlled normothermia) for another $24 \mathrm{hr}$ \\
\hline \multirow[t]{2}{*}{25} & Use intermittent pneumatic compression device for DVT prophylaxis \\
\hline & I - Infectious diseases \\
\hline \multirow[t]{2}{*}{26} & Screen for infection if systemic vascular resistance persistently low \\
\hline & Neuroprognostication \\
\hline 27 & $\begin{array}{l}\text { Delayed neuroprognostication ( } 72 \mathrm{hr} \text { after returning to normothermia) in view of reduced metabolism of sedatives and } \\
\text { neuromuscular blocking agents during hypothermia therapy }\end{array}$ \\
\hline 28 & Use a multimodal strategy for neuroprognostication and not based on any single finding alone \\
\hline 29 & Consider sensitivity and specificity of each test before making decision on withdrawal of life-sustaining therapy \\
\hline
\end{tabular}

AKI: acute kidney injury; BP: blood pressure; CEEG: continuous electroencephalography; DVT: deep venous thrombosis; ECG: electrocardiogram; ETT: endotracheal tube; $\mathrm{FiO}_{2}$ : fraction of inspired oxygen; ICP: intracranial pressure; IHCA: in-hospital cardiac arrest; MAP: mean arterial pressure; OHCA: out-of-hospital cardiac arrest; ONSD: optic nerve sheath diameter; PBW: predicted body weight; PEEP: positive end expiratory pressure; ROSC: return of spontaneous circulation; $\mathrm{ScvO}_{2}$ : central venous oxygen saturation; STEMI: ST-segment elevation myocardial infarction; TTM: targeted temperature management; VAP: ventilator-associated pneumonia 


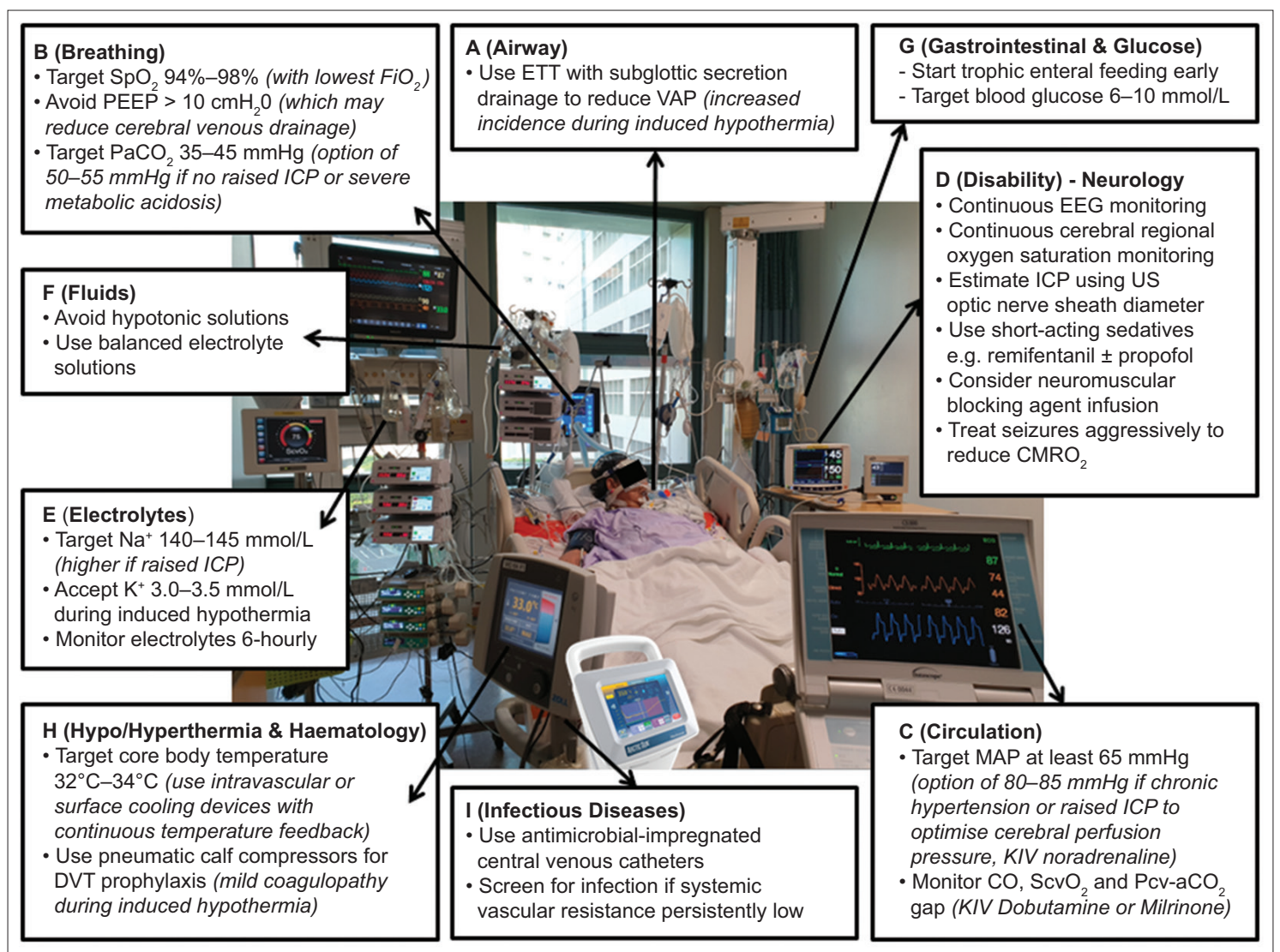

Fig. 1 Management of post-cardiac arrest syndrome: the 'A to I' approach. DVT: deep venous thrombosis; EEG: electroencephalography; ETT: endotracheal tube; ICP: intracranial pressure; KIV: keep in view; MAP: mean arterial pressure; PEEP: positive end expiratory pressure; $\mathrm{ScvO}_{2}$ : central venous oxygen saturation; US: ultrasonography; VAP: ventilator-associated pneumonia [adapted with permission from Ng S and Chia YW]. (30)

no need to intervene if the patient develops sinus bradycardia with a heart rate of $30-40 / \mathrm{min}$, if the $\mathrm{BP}, \mathrm{ScvO}_{2}$ and lactate clearance are adequate. However, if there is advanced atrioventricular block, the target temperature can be increased slightly, up to $36^{\circ} \mathrm{C}$.

\section{Haemodynamic support}

Post-resuscitation myocardial dysfunction causes haemodynamic instability, manifesting as hypotension, low cardiac output and arrhythmias. ${ }^{(24)}$ Myocardial dysfunction often requires inotropic support, with dobutamine having the most evidence for use. ${ }^{(25)}$ However, the systemic inflammatory response syndrome (SIRS) that occurs in PCAS also causes vasodilation and, sometimes, vasoplegia. If vasoplegia predominates, it is recommended to start noradrenaline first to achieve haemodynamic targets and also because it is less arrhythmogenic. ${ }^{(26)}$ However, if up-titration of noradrenaline reduces stroke volume or $\mathrm{ScvO}_{2}$ (suggesting an excessive increase in left ventricular afterload causing a drop in cardiac output), it may be useful to add on a low-dose inotrope (e.g. dobutamine $3-5 \mathrm{mcg} / \mathrm{kg} / \mathrm{min}$ ). Noradrenaline, with or without an inotrope, is usually the most effective therapeutic regime.

\section{D - DISABILITY (NEUROLOGY) Indications for computed tomography}

In the absence of preceding cardiac symptoms and ischaemic ECG changes, and/or in the presence of symptoms or signs suggestive of a neurological cause (headache, seizures, focal neurological deficits) for the cardiac arrest, computed tomography (CT) of the head should be considered. ${ }^{(27)}$ Similarly, if a respiratory cause (dyspnoea, hypoxia in patients with known respiratory disease) is suspected, CT of the thorax should be considered.

\section{Cerebral monitoring}

Seizures are common after anoxic brain injury and occur in approximately one-third of patients who remain comatose after ROSC. Therefore, patients should be on continuous electroencephalography (cEEG) monitoring. If cEEG is not available, limited evidence suggests that sedation monitors may be helpful, as they provide four channels of continuous frontal EEG monitoring. A spot EEG should be obtained whenever there is clinical suspicion of seizures if patient is not already on EEG monitoring. In addition, cerebral blood flow and cerebral tissue oxygenation may be indirectly monitored using nearinfrared spectroscopy to measure cerebral regional oxygen saturation $\left(\mathrm{rSO}_{2}\right)^{.}{ }^{(28-30)}$ The use of cerebral $\mathrm{rSO}_{2}$ is useful to guide management. For example, up-titration of noradrenaline to achieve a particular MAP target may result in decreased cerebral blood flow from cerebral vasoconstriction and/or a drop in stroke volume from increased left ventricular afterload. The decrease in cerebral blood flow will manifest as a drop in cerebral $\mathrm{rSO}_{2}$. A drop in $\mathrm{rSO}_{2}$ can also be an early warning of hypocapnia from hyperventilation to reduce ICP or after the start of neuromuscular blocking agent for shivering during induction of hypothermia. ${ }^{(14,28)}$ 


\section{Sedation}

Adequate sedation reduces oxygen consumption and improves the balance between oxygen supply and demand. Sedation also helps to reduce the incidence of shivering during induced hypothermia. It is also important to start sedation if neuromuscular blocking agents are used, to prevent awareness during paralysis. Although there is no data to support whether the choice of agents affects outcome, it is recommended to use short-acting drugs (e.g. remifentanil and propofol), as they allow more reliable and earlier neurological assessment. ${ }^{(31)}$ This is especially important, as the metabolism of sedatives and neuromuscular blocking agents is reduced with hypothermia.

\section{Paralysis}

Limited data suggests that continuous infusion of neuromuscular blocking agents is associated with decreased mortality in PCAS. ${ }^{(32)}$ However, the use of neuromuscular blocking agents interferes with clinical examination and masks seizures. Therefore, cEEG or a sedation monitor with continuous frontal EEG monitoring should be utilised whenever patients are on paralytics. ${ }^{(33)}$

\section{Seizures}

Myoclonus is the most common seizure and occurs in 18\%-25\% of patients, the remainder being focal or generalised tonic-clonic seizures. ${ }^{(34)}$ Seizures increase the cerebral metabolic rate of oxygen $\left(\mathrm{CMRO}_{2}\right)$ and can potentially result in secondary brain injury. They should be treated aggressively, and the recommended options are levetiracetam and sodium valproate, as they have less adverse cardiac effects.

\section{E - ELECTROLYTES}

Regarding serum electrolytes, aim for normal sodium level (e.g. 140-145 mmol/L), but if ICP is raised, the target can be increased (e.g. to 150-155 mmol/L). Mild hypokalaemia during hypothermia is common because of cold diuresis and transcellular shift. Accept mild hypokalaemia (e.g. $3.0-3.5 \mathrm{mmol} / \mathrm{L}$ ) if there are no significant arrhythmias, and avoid aggressive replacement to prevent rebound hyperkalaemia during subsequent rewarming.

\section{F - FLUIDS}

\section{Choice of fluids}

Cerebral oedema may occur transiently after ROSC, but it is rarely associated with a clinically relevant increase in ICP. Nonetheless, it is important to avoid hypotonic solutions, which may worsen brain swelling. Balanced electrolyte solutions such as lactated Ringer's Solution and Plasma-Lyte A are recommended. These potassium-containing fluids may also help to reduce the hypokalaemia commonly encountered during hypothermia.

\section{G - GASTROINTESTINAL FEEDING AND GLUCOSE}

Early enteral feeding is recommended as per standard ICU practice to reduce infectious complications. However, feeding should be started at low rates (trophic feeding), as hypothermia may lead to gastroparesis and prolonged intestinal transit time. There could be high gastric residual volume requiring the use of prokinetic agents. A combination of metoclopramide and erythromycin has been shown to have synergistic effects in reducing gastric residual volume. ${ }^{(35)}$ Monitor for QT interval prolongation if the patient is on both erythromycin and hypothermia therapy.

Both low and high blood glucose levels have adverse effects on the neurological prognosis. ${ }^{(36)}$ Hypothermia is associated with both hyperglycaemia (because of reduced insulin sensitivity) and increased blood glucose variability, both of which are associated with increased mortality and unfavourable neurological outcomes after cardiac arrest. Based on the available data, the recommendation is to target normoglycaemia (e.g. blood glucose 6-10 mmol/L). Use intravenous insulin infusion, rather than subcutaneous insulin, to control blood glucose levels when the patient is on vasopressors and/or hypothermia therapy, as subcutaneous absorption may be erratic.

\section{H - HYPOTHERMIA/HYPERTHERMIA}

TTM includes both targeted hypothermia (targeting core body temperature $32^{\circ} \mathrm{C}-34^{\circ} \mathrm{C}$ ) and targeted normothermia (targeting core body temperature $35^{\circ} \mathrm{C}-37^{\circ} \mathrm{C}$ ). Guidelines advocate TTM for all adult patients with $\mathrm{OHCA}$ and in-hospital cardiac arrest (IHCA) who remain comatose after ROSC regardless of initial cardiac rhythm..$^{(18,19)} \mathrm{A}$ target temperature of $32^{\circ} \mathrm{C}-36^{\circ} \mathrm{C}$ should be selected, achieved and maintained consistently for at least 24 hours. Data indicates that mild hypothermia is neuroprotective and improves outcomes after ROSC. ${ }^{(37-39)}$ Cooling suppresses pathways that lead to apoptosis, decreases $\mathrm{CMRO}_{2}$ by $6 \%$ with every degree Celsius reduction in core body temperature, and reduces the release of excitatory amino acids and free radicals. Conversely, several studies have documented an association between post-cardiac arrest pyrexia and poor neurological outcomes. ${ }^{(40)}$ Therefore, it is reasonable to treat hyperthermia occurring after cardiac arrest with antipyretics and consider the use of active cooling.

The 2013 TTM Trial randomised 950 patients with OHCA to $\mathrm{TTM}$ at $33^{\circ} \mathrm{C}$ vs. $36^{\circ} \mathrm{C}$, and the results showed no difference in all-cause mortality or neurological outcomes at the 180-day follow-up. ${ }^{(41)}$ Unfortunately, this led to some centres misinterpreting the trial results and abandoning TTM use altogether. It is important to note that the TTM Trial had two active treatment arms (i.e. TTM at $33^{\circ} \mathrm{C}$ vs. $\mathrm{TTM}_{\mathrm{T}} 36^{\circ} \mathrm{C}$ ). It was not a trial of TTM versus no TTM. Active temperature management was also advocated for patients randomised to the $36^{\circ} \mathrm{C}$ arm. Centres that have changed their target temperature from $33^{\circ} \mathrm{C}$ to $36^{\circ} \mathrm{C}$ have shown that maintenance of target temperature at $36^{\circ} \mathrm{C}$ is technically more challenging compared to $33^{\circ} \mathrm{C}$ (time in target temperature $50 \%$ vs. $87 \%$ ), as is the avoidance of pyrexia (incidence of fever $19 \%$ vs. $0 \%$ ), with a trend towards increased mortality. ${ }^{(42)}$ Therefore, it is important for ICUs adopting a strategy of $\mathrm{TTM}$ at $36^{\circ} \mathrm{C}$ to be aware that patients on targeted normothermia still require active temperature management, including the use of sedatives, neuromuscular blocking agents and cooling devices, to minimise fluctuations in temperature and prevent fever.

In line with international guidelines, the Singapore National TTM Workgroup recommends TTM for all adult patients with ROSC after 
OHCA or IHCA who are unable to obey commands (Glasgow motor score $<6$ ), regardless of initial cardiac rhythm (i.e. VF, ventricular tachycardia, pulseless electrical activity or asystole). ${ }^{(18,19,43)}$

Exclusion criteria for TTM: (a) patients deemed unsuitable for further resuscitation; and/or (b) patients with baseline Cerebral Performance Category 3 or 4 . (Note that bleeding diathesis, sepsis, bradycardia and prolonged QT interval are not contraindications to TTM. Cardiac arrest patients with these conditions will still benefit from TTM, but a higher target temperature may be selected, up to $36^{\circ} \mathrm{C}$.)

We recommend targeting a temperature of $33^{\circ} \mathrm{C}$ for PCAS (range $32^{\circ} \mathrm{C}-34^{\circ} \mathrm{C}$ ). However, for patients who are intolerant of $33^{\circ} \mathrm{C}$ (e.g. those with bleeding diathesis, significant bradycardia or marked QT interval prolongation), it is reasonable to aim for a higher target temperature of up to $36^{\circ} \mathrm{C}$. A cooling method with effective temperature monitoring that minimises temperature fluctuations is preferred. This is best achieved with internal or external cooling devices that have continuous temperature feedback to achieve a set target temperature, using thermistors placed in the oesophagus or urinary bladder to monitor the core body temperature. ${ }^{(44)}$ Temperature should be monitored continuously and recorded at least hourly in the clinical charts. Endovascular cooling catheters and gel-coated adhesive cooling pads provide more rapid hypothermia induction and more effective temperature maintenance with minimal fluctuations compared to water-circulating cooling blankets. ${ }^{(45)}$

\section{Induction phase}

a) If target temperature is $33^{\circ} \mathrm{C}$ and the patient's temperature is below $33^{\circ} \mathrm{C}$, allow passive (not active) rewarming to $33^{\circ} \mathrm{C}$, and then start endovascular or surface cooling to maintain the temperature at $33^{\circ} \mathrm{C}$.

b) If target temperature is $33^{\circ} \mathrm{C}$ and the patient's temperature is above $33^{\circ} \mathrm{C}$, start endovascular or surface cooling to reach the target temperature of $33^{\circ} \mathrm{C}$. Avoid rapid infusion of large volumes of cold fluids, which have been shown to cause pulmonary oedema and recurrent cardiac arrest.

c) If target temperature is $36^{\circ} \mathrm{C}$ and the patient's temperature is below $36^{\circ} \mathrm{C}$, allow passive (not active) rewarming to $36^{\circ} \mathrm{C}$, and then start endovascular or surface cooling to maintain the temperature at $36^{\circ} \mathrm{C}$.

d) If target temperature is $36^{\circ} \mathrm{C}$ and the patient's temperature is above $36^{\circ} \mathrm{C}$, start endovascular or surface cooling to reach the target temperature of $36^{\circ} \mathrm{C}$.

\section{Maintenance phase}

Maintain the patient at the target temperature for at least 24 hours after reaching the target temperature. It may be reasonable to consider maintaining a longer duration at the target temperature for patients who have a longer duration of no flow and/or low flow time. ${ }^{(46)}$ Shivering increases metabolic rate and causes heat production. The occurrence of shivering in patients who undergo mild hypothermia is associated with better neurological outcomes as it is a sign of normal physiological response. Management of shivering includes: (a) skin counter-warming; (b) intravenous magnesium; (c) increasing sedation; and (d) starting paralytics (put on cEEG or sedation monitoring, as seizures will be masked).

\section{Rewarming phase}

Rewarm the patient very gradually (e.g. at $0.1^{\circ} \mathrm{C}-0.25^{\circ} \mathrm{C}$ per hour) until the temperature reaches $37^{\circ} \mathrm{C}$, and maintain the temperature at $37^{\circ} \mathrm{C}$ (controlled normothermia) for another 24 hours. The development of hyperthermia after induced mild hypothermia (i.e. rebound hyperthermia) is associated with increased mortality and worse neurological outcomes. ${ }^{(47,48)}$ Therefore, slow, controlled rewarming at $0.1^{\circ} \mathrm{C}-0.25^{\circ} \mathrm{C}$ per hour is recommended. Other effects during rewarming include: (a) increased oxygen consumption; (b) increased $\mathrm{CO}_{2}$ production from increased metabolic activities (may need to increase minute volume to maintain normocapnia); (c) hypotension from vasodilation (do not wean off noradrenaline too early); (d) tachyarrhythmias, which may cause myocardial ischaemia; (e) cerebral desaturation from increased $\mathrm{CMRO}_{2}$ (continue to monitor cerebral $\mathrm{rSO}_{2}$ ); (f) seizures from lowering in seizure threshold (continue to monitor EEG); (g) rebound hyperkalaemia from transcellular shift (keep potassium low-normal before rewarming); and (h) hypoglycaemia from increased insulin sensitivity (may need to reduce insulin infusion).

\section{H - HAEMATOLOGY}

Hypothermia results in mild coagulopathy. However, there is usually no clinically significant bleeding and, therefore, the use of antiplatelets and anticoagulants is not contraindicated. However, if there is bleeding, a higher target temperature may be selected, up to $36^{\circ} \mathrm{C}$. Intermittent pneumatic compression device should be applied for deep venous thrombosis prophylaxis.

\section{I - INFECTIOUS DISEASES}

There is a higher incidence of lower respiratory tract infections with hypothermia therapy because of mild immune paresis. ${ }^{(6)}$ However, there is no current recommendation for prophylactic antibiotics. ${ }^{(49)}$ The SIRS response in PCAS should resolve in the first 24-48 hours after cardiac arrest. If systemic vascular resistance remains persistently low, screen for sepsis and check infective markers, as the patient will not mount a fever response during TTM.

\section{NEUROPROGNOSTICATION}

A multimodal strategy, comprising clinical examination, somatosensory-evoked potentials, EEG, serum biomarkers of neuronal damage and cerebral imaging, should be used for neuroprognostication. ${ }^{(50)}$ The clearance of sedative drugs and neuromuscular blocking agents can be reduced by up to $30 \%$ at a core body temperature of $34^{\circ} \mathrm{C}$. Therefore, in patients who are cooled to $32^{\circ} \mathrm{C}-34^{\circ} \mathrm{C}$, neuroprognostication using clinical examination should be delayed until 72 hours after returning to normothermia. ${ }^{(18)}$ Accurate neurological prognostication in brain-injured cardiac arrest survivors is crucial to ensure that patients with potential for meaningful recovery are not destined for certain poor outcomes because of withdrawal of life-sustaining therapy. 


\section{CONCLUSION}

Post-cardiac arrest care is a critical link in the chain of survival and demands a comprehensive, structured, multisystem approach to improve neurologically intact survival. The quality of postresuscitation ICU care has a major influence on the final clinical outcome. If a patient with cardiac arrest is 'fortunate' enough to be successfully resuscitated, he or she deserves the best chance for a good long-term prognosis.

\section{CASE VIGNETTE (PART 2)}

The patient was ventilated with a lung protective strategy with low PEEP of $5 \mathrm{cmH}_{2} \mathrm{O}$, accepting $\mathrm{SpO}_{2} 95 \%$. Her haemodynamics were supported with intra-aortic balloon pump counterpulsation, noradrenaline and vasopressin. Ultrasonography ONSD was $7 \mathrm{~mm}$, indicating a raised ICP of $>20 \mathrm{cmH}_{2} \mathrm{O}$. Therefore, the MAP target was set at $80-85 \mathrm{mmHg}$ to optimise cerebral perfusion pressure. Osmotherapy with hypertonic saline was also started to lower ICP, aiming for a sodium target of 150-155 mmol/L. $\mathrm{PaCO}_{2}$ was lowered gradually from $55 \mathrm{mmHg}$, with continuous cerebral $\mathrm{rSO}_{2}$ monitoring. It was noted that cerebral $\mathrm{rSO}_{2}$ plummeted from $48 \%$ to $41 \%$ when $\mathrm{PaCO}_{2}$ reached $37 \mathrm{mmHg}$. Therefore, $\mathrm{PaCO}_{2}$ target was set at $40-45 \mathrm{mmHg}$. Hypercapnia was avoided because of raised ICP.

Continuous cardiac output monitoring revealed a cardiac index of $2.3 \mathrm{~L} / \mathrm{min} / \mathrm{m}^{2}$, a mixed venous oxygen saturation $\left(\mathrm{SvO}_{2}\right)$ of $67 \%$ with $\mathrm{Pmv}_{-} \mathrm{aCO}_{2}$ gap of $10 \mathrm{mmHg}$ and arterial lactate $>10.8 \mathrm{mmol} / \mathrm{L}$, suggesting a low flow state. Therefore, low-dose dobutamine was added, which led to an increase in cardiac index to $3.0 \mathrm{~L} / \mathrm{min} / \mathrm{m}^{2}$, an increase in $\mathrm{SvO}_{2}$ to $76 \%$, a reduction in $\mathrm{Pmv}_{-} \mathrm{aCO}_{2}$ gap to $5 \mathrm{mmHg}$ and a drop in lactate to $4.5 \mathrm{mmol} / \mathrm{L}$. Cerebral $\mathrm{rSO}_{2}$ also increased to $59 \%$ after dobutamine was started, reflecting an increase in cerebral blood flow.

On arrival in the cardiac ICU, the patient was commenced on intravascular temperature management, reaching a target temperature of $33^{\circ} \mathrm{C}$ from $35.8^{\circ} \mathrm{C}$ within 45 minutes. Repeat ultrasonography ONSD at 24 hours revealed that the ICP was still elevated and, therefore, rewarming was not attempted. She was maintained at target temperature for about 72 hours and gradually rewarmed when ONSD had normalised. She was rewarmed at $0.1^{\circ} \mathrm{C}$ per hour to $37^{\circ} \mathrm{C}$ (over 40 hours) and maintained at $37^{\circ} \mathrm{C}$ (controlled normothermia) for another 24 hours.

The patient woke up after reaching normothermia when atracurium and remifentanil were weaned off. She was able to obey commands and recognise her family members. She was subsequently extubated and transferred to the general ward. The patient was in Cerebral Performance Category 1 with a normal neurocognitive assessment before discharge.

\section{REFERENCES}

1. White AE, Poh JS, Pek PP, et al. Singapore out-of-hospital cardiac arrest registry report 2011-2018. November 2020. Republic of Singapore. Unit for Prehospital Emergency Care. Available at: https://www.myheart.org.sg/wp-content/ uploads/2021/01/Singapore-OHCA-Data-Report-2011-2018.pdf. Accessed May 15,2021

2. Nolan JP, Neumar RW, Adrie C, et al. Post-cardiac arrest syndrome: epidemiology, pathophysiology, treatment, and prognostication. A Scientific Statement from the International Liaison Committee on Resuscitation; the
American Heart Association Emergency Cardiovascular Care Committee; the Council on Cardiovascular Surgery and Anesthesia; the Council on Cardiopulmonary, Perioperative, and Critical Care; the Council on Clinical Cardiology; the Council on Stroke. Resuscitation 2008; 79:350-79.

3. Gaieski DF, Band RA, Abella BS, et al. Early goal-directed hemodynamic optimization combined with therapeutic hypothermia in comatose survivors of out-of-hospital cardiac arrest. Resuscitation 2009; 80:418-24.

4. Leong SH, Chan E, Ho BC, et al. Therapeutic temperature management (TTM): post-resuscitation care for adult cardiac arrest, with recommendations from the National TTM Workgroup. Singapore Med J 2017; 58:408-10.

5. Berg KM, Soar J, Andersen LW, et al. Adult advanced life support: 2020 international consensus on cardiopulmonary resuscitation and emergency cardiovascular care science with treatment recommendations. Circulation 2020; 142(16 Suppl 1):S92-139.

6. Geurts M, Macleod MR, Kollmar R, Kremer PH, van der Worp HB. Therapeutic hypothermia and the risk of infection: a systematic review and meta-analysis. Crit Care Med 2014; 42:231-42.

7. Muscedere J, Rewa O, McKechnie K, et al. Subglottic secretion drainage for the prevention of ventilator-associated pneumonia: a systematic review and meta-analysis. Crit Care Med 2011; 39:1985-91

8. Wang $\mathrm{CH}$, Chang WT, Huang $\mathrm{CH}$, et al. The effect of hyperoxia on survival following adult cardiac arrest: a systematic review and meta-analysis of observational studies. Resuscitation 2014; 85:1142-8.

9. Elmer J, Scutella M, Pullalarevu R, et al. The association between hyperoxia and patient outcomes after cardiac arrest: analysis of a high-resolution database. Intensive Care Med 2015; 41:49-57.

10. Schneider AG, Eastwood GM, Bellomo R, et al. Arterial carbon dioxide tension and outcome in patients admitted to the intensive care unit after cardiac arrest. Resuscitation 2013; 84:927-34.

11. Roberts BW, Kilgannon JH, Chansky ME, et al. Association between postresuscitation partial pressure of arterial carbon dioxide and neurological outcome in patients with post-cardiac arrest syndrome. Circulation 2013; 127:2107-13.

12. Eastwood GM, Tanaka A, Bellomo R. Cerebral oxygenation in mechanically ventilated early cardiac arrest survivors: the impact of hypercapnia. Resuscitation 2016; 102:11-6.

13. Eastwood GM, Schneider AG, Suzuki S, et al. Targeted therapeutic mild hypercapnia after cardiac arrest: a phase II multi-centre randomised controlled trial (the CCC trial). Resuscitation 2016; 104:83-90.

14. Falkenbach $P$, Kämäräinen $A$, Mäkelä A, et al. Incidence of iatrogenic dyscarbia during mild therapeutic hypothermia after successful resuscitation from out-ofhospital cardiac arrest. Resuscitation 2009; 80:990-3.

15. Larsen JM, Ravkilde J. Acute coronary angiography in patients resuscitated from out-of-hospital cardiac arrest--a systematic review and metaanalysis. Resuscitation 2012; 83:1427-33.

16. Callaway CW, Schmicker RH, Brown SP, et al. Early coronary angiography and induced hypothermia are associated with survival and functional recovery after out-of-hospital cardiac arrest. Resuscitation 2014; 85:657-63.

17. Ibanez B, James S, Agewall S, et al. 2017 ESC guidelines for the management of acute myocardial infarction in patients presenting with ST-segment elevation: the Task Force for the management of acute myocardial infarction in patients presenting with ST-segment elevation of the European Society of Cardiology (ESC). Eur Heart J 2018; 39:119-77.

18. Panchal AR, Bartos JA, Cabañas JG, et al. Part 3: adult basic and advanced life support: 2020 American Heart Association guidelines for cardiopulmonary resuscitation and emergency cardiovascular care. Circulation 2020; 142(16 Suppl 2):S366-468.

19. Nolan JP, Sandroni C, Böttiger BW, et al. European Resuscitation Council and European Society of Intensive Care Medicine guidelines 2021: post-resuscitation care. Resuscitation 2021; 161:220-69.

20. Hollenbeck RD, McPherson JA, Mooney MR, et al. Early cardiac catheterization is associated with improved survival in comatose survivors of cardiac arrest without STEMI. Resuscitation 2014; 85:88-95.

21. Kimberly HH, Shah S, Marill K, Noble V. Correlation of optic nerve sheath diameter with direct measurement of intracranial pressure. Acad Emerg Med 2008; 15:201-4.

22. Ameloot K, Genbrugge C, Meex I, et al. An observational near-infrared spectroscopy study on cerebral autoregulation in post-cardiac arrest patients: time to drop 'one-size-fits-all' hemodynamic targets? Resuscitation 2015; 90:121-6.

23. Stær-Jensen $H$, Sunde K, Olasveengen TM, et al. Bradycardia during therapeutic hypothermia is associated with good neurologic outcome in comatose survivors of out-of-hospital cardiac arrest. Crit Care Med 2014; 42:2401-8.

24. Laurent I, Monchi M, Chiche JD, et al. Reversible myocardial dysfunction in survivors of out-of-hospital cardiac arrest. J Am Coll Cardiol 2002; 40:2110-6.

25. Vasquez A, Kern KB, Hilwig RW, et al. Optimal dosing of dobutamine for treating post-resuscitation left ventricular dysfunction. Resuscitation 2004; 61:199-207.

26. De Backer D, Biston P, Devriendt J, et al. Comparison of dopamine and norepinephrine in the treatment of shock. N Engl J Med 2010; 362:779-89.

27. Chelly J, Mongardon N, Dumas F, et al. Benefit of an early and systematic 
imaging procedure after cardiac arrest: insights from the PROCAT (Parisian Region Out of Hospital Cardiac Arrest) registry. Resuscitation 2012; 83:1444-50.

28. Bouzat P, Suys T, Sala N, Oddo M. Effect of moderate hyperventilation and induced hypertension on cerebral tissue oxygenation after cardiac arrest and therapeutic hypothermia. Resuscitation 2013; 84:1540-5.

29. Ahn A, Yang J, Inigo-Santiago L, Parnia S. A feasibility study of cerebral oximetry monitoring during the post-resuscitation period in comatose patients following cardiac arrest. Resuscitation 2014; 85:522-6.

30. Ng S, Chia YW. A case report: use of cerebral oximetry in the early detection of cerebral hypoperfusion in a post-cardiac arrest patient during targeted temperature management. Eur Heart J Case Rep 2019; 3:ytz125.

31. Bjelland TW, Dale O, Kaisen K, et al. Propofol and remifentanil versus midazolam and fentanyl for sedation during therapeutic hypothermia after cardiac arrest: a randomised trial. Intensive Care Med 2012; 38:959-67.

32. Salciccioli JD, Cocchi MN, Rittenberger JC, et al. Continuous neuromuscular blockade is associated with decreased mortality in post-cardiac arrest patients. Resuscitation 2013; 84:1728-33.

33. Rundgren M, Westhall E, Cronberg T, Rosén I, Friberg H. Continuous amplitudeintegrated electroencephalogram predicts outcome in hypothermia-treated cardiac arrest patients. Crit Care Med 2010; 38:1838-44.

34. Snyder BD, Hauser WA, Loewenson RB, et al. Neurologic prognosis after cardiopulmonary arrest: III. Seizure activity. Neurology 1980; 30:1292-7.

35. Nguyen NQ, Chapman M, Fraser RJ, et al. Prokinetic therapy for feed intolerance in critical illness: one drug or two? Crit Care Med 2007; 35:2561-7.

36. Daviaud F, Dumas F, Demars N, et al. Blood glucose level and outcome after cardiac arrest: insights from a large registry in the hypothermia era. Intensive Care Med 2014; 40:855-62.

37. Polderman KH. Mechanisms of action, physiological effects, and complications of hypothermia. Crit Care Med 2009; 37(7 Suppl):S186-202.

38. Hypothermia after Cardiac Arrest Study Group. Mild therapeutic hypothermia to improve the neurologic outcome after cardiac arrest. N Engl J Med 2002 346:549-56. Erratum in: N Engl J Med 2002; 346:1756.

39. Bernard SA, Gray TW, Buist MD, et al. Treatment of comatose survivors of out-of-hospital cardiac arrest with induced hypothermia. N Engl J Med 2002; 346:557-63.

40. Diringer MN, Reaven NL, Funk SE, Uman GC. Elevated body temperature independently contributes to increased length of stay in neurologic intensive care unit patients. Crit Care Med 2004; 32:1489-95. Erratum in: Crit Care Med 2004; 32:2170.

41. Nielsen N, Wetterslev J, Cronberg T, et al. Targeted temperature management at $33^{\circ} \mathrm{C}$ versus $36^{\circ} \mathrm{C}$ after cardiac arrest. N Engl J Med 2013; 369:2197-206.

42. Bray JE, Stub D, Bloom JE, et al. Changing target temperature from $33^{\circ} \mathrm{C}$ to $36^{\circ} \mathrm{C}$ in the ICU management of out-of-hospital cardiac arrest: a before and after study. Resuscitation 2017; 113:39-43.

43. Lascarrou JB, Merdji H, Le Gouge A, et al. Targeted temperature management for cardiac arrest with nonshockable rhythm. N Engl J Med 2019; 381:2327-37.

44. Knapik P, Rychlik W, Duda D, et al. Relationship between blood, nasopharyngeal and urinary bladder temperature during intravascular cooling for therapeutic hypothermia after cardiac arrest. Resuscitation 2012; 83:208-12.

45. Sonder P, Janssens GN, Beishuizen A, et al. Efficacy of different cooling technologies for therapeutic temperature management: a prospective intervention study. Resuscitation 2018; 124:14-20.

46. Kirkegaard H, Søreide E, de Haas I, et al. Targeted temperature management for 48 vs 24 hours and neurologic outcome after out-of-hospital cardiac arrest: a randomized clinical trial. JAMA 2017; 318:341-50.

47. Winters SA, Wolf $\mathrm{KH}$, Kettinger SA, et al. Assessment of risk factors for postrewarming "rebound hyperthermia" in cardiac arrest patients undergoing therapeutic hypothermia. Resuscitation 2013; 84:1245-9.

48. Bro-Jeppesen J, Hassager C, Wanscher M, et al. Post-hypothermia fever is associated with increased mortality after out-of-hospital cardiac arrest. Resuscitation 2013; 84:1734-40.

49. François B, Cariou A, Clere-Jehl R, et al. Prevention of early ventilator-associated pneumonia after cardiac arrest. N Engl J Med 2019; 381:1831-42

50. Gaieski DF, Goyal M, Perman SM. "Are you sure she will not recover?" Multimodal prognostication provides increased certainty about poor outcomes prediction. Crit Care Med 2014; 42:1535-6. 